+ Addecott, K. S. B., and Nutt, C. W., Am. Chem. Soc. Div. Petrochem., 14 (4), A69-80 (1969).

Cotton, D. H., Friswell, N. J., and Jenkins, D. R., Combustion and Flame, 17, 87-98 (1971).

Salooja, K. C., Nature, 240, 350-351 (1972)

Salooja, K. C., Combustion Institute European Symposium (edit. by Weinberg, F. J.) 400-405 (Academic Press, London, 1973).

${ }^{8}$ Feugier, A., ibid, 406-411.

\section{Radicals in irradiated ethyl iodide and related compounds}

IN studies of the radiolysis of various alkyl halides, particular attention has been focused on a multiline electron spin resonance (ESR) spectrum obtained from ethyl iodide at $77 \mathrm{~K}$ (ref. 1). Despite the use of a wide range of isotopically enriched materials, however, there has been no satisfactory interpretation of these complex ESR spectra and this remains one of the unsolved problems of ESR spectroscopy ${ }^{2}$.

The spectrum for normal $\mathrm{CH}_{3} \mathrm{CH}_{2} \mathrm{I}$ comprises sets of 'parallel' and 'perpendicular' type features covering a total range of about 1,000 gauss which seem, in the outer regions of the spectra, to comprise sextets with $a \approx 22$ gauss. These are centred close to the free-spin $g$ value (see Figures in ref. 1).

Studies of other alkyl halides ${ }^{3-5}$, indicate that the most likely candidates are the $\alpha$ - or $\beta$-iodo alkyl radicals (Fig. 1, I and II). Radical I is however, expected to exhibit a very marked $g$-value variation which would lead to considerable spectral asymmetry,

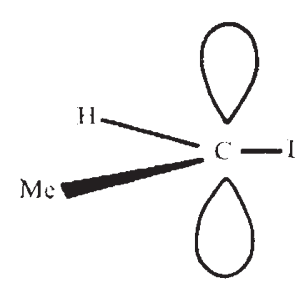

I

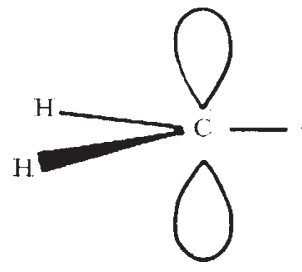

II
Fig. 1

with strong features in the region of low-field, and even if these radicals were librating or rotating the resulting $g_{\text {av }}$ value would be $>>2.0023$. This is not observed, and indeed, the spectra are completely different from that obtained from irradiated $\alpha$-iodo acetamide, which we assign to $\mathrm{HCI}\left(\mathrm{CONH}_{2}\right)$ radicals (G. W. Neilson, and S. P. Mishra, unpublished results).

Again, the $\beta$-iodo radical, II, is expected to have a far larger hyperfine coupling to ${ }^{127} \mathrm{I}$ than is possible for the ethyl iodide radical, and the $\alpha$-proton coupling should give rise to a triplet having $a \leqslant 20$ gauss. (Coupling to the two $\beta$-protons should be small.)

Thus I and II can be firmly rejected. The radical $\mathrm{CH}_{3} \mathrm{CH}_{2}$ $---\mathrm{I}^{-}$is, however, a likely candidate. Methyl bromide in a methyl cyanide matrix gives a species $\mathrm{CH}_{3}---\mathrm{Br}^{-}$, which has the normal magnetic properties for methyl radicals, but with each feature split into a pair of quartets by hyperfine coupling to ${ }^{79} \mathrm{Br}$ and ${ }^{81} \mathrm{Br}$ (ref. 6). We have extended this work to include methyl iodide, which again gave a spectrum characteristic of methyl, with a weak hyperfine coupling to iodine ${ }^{7}$ (Table 1).

We find that the spectra published by Willard et al. ${ }^{1}$, and ourselves for normal $\mathrm{CH}_{3} \mathrm{CH}_{2} \mathrm{I}$ can be quite satisfactorily analysed on this hypothesis, using the parameters given in Table 1. In particular, the 22 gauss sextets have their $\pm 5 / 2$ components broadened, as is usually the case for ethyl radicals in rigid media, and therefore could be mistaken for quartets $(1: 3: 3: 1)$, thus closely resembling the features for $\mathrm{CH}_{3} \mathrm{CD}_{2}-\cdots \mathrm{I}^{-}$, as noted by Willard et al. ${ }^{1}$.

Comparable species were not obtained from methyl iodide or from solutions of ethyl iodide in $\mathrm{CD}_{3} \mathrm{OD}$. A very similar
Table 1 ESR parameters for $\mathrm{CH}_{3} \mathrm{CH}_{2}-\ldots \mathrm{I}^{-}$and related anions

\begin{tabular}{|c|c|c|}
\hline Medium & Radical & $\begin{array}{l}\text { Hyperfine coupling (gauss) } \\
{ }^{1} \mathrm{H}\end{array}$ \\
\hline $\begin{array}{l}\mathrm{CD}_{3} \mathrm{OD} \\
\mathrm{C}_{2} \mathrm{H}_{5} \mathrm{I} \\
\mathrm{Me}_{3} \mathrm{CI}\end{array}$ & $\begin{array}{l}\mathrm{CH}_{3}---\mathrm{I}^{-} \\
\mathrm{CH}_{3} \mathrm{CH}_{2}---\mathrm{I}^{-} \\
\mathrm{Me}_{3} \mathrm{C}-\cdots-\mathrm{I}^{-}\end{array}$ & $\begin{array}{lll}21 & (\|) 78 & (\perp) 56 \\
22 & (\text { (I) } 168 & (\stackrel{\perp}{\perp}) 126 \\
22 & (\|)>53.5 & (\stackrel{1}{1}) 53.5\end{array}$ \\
\hline
\end{tabular}

*, 1 gauss $-10^{-4} \mathrm{~T}$;

$\uparrow$, all $g$ values close to 2.0023 ;

\pm , ref. 6 .

species, $(\mathrm{Me})_{3} \mathrm{C} \cdot-\cdots \mathrm{I}^{-}$, was, however, obtained from t-butyliodide (Table 1).

We conclude that the process involved is

$$
\mathrm{RI}+\mathrm{e}^{-} \rightarrow \mathrm{R}---\mathrm{I}^{-}
$$

in which the radical, $\mathrm{R}$, has its normal planar geometry, but, under favourable circumstances, exhibits a very weak chargetransfer interaction with iodide. We suggest that the occurrence of this interaction, and its magnitude, is governed primarily by the crystal structure of the host compound and therefore by the mobility of the alkyl radical. The results for $\mathrm{CD}_{3} \mathrm{OD}$ solution show that the interaction is lost when iodide can be solvated, even at $77 \mathrm{~K}$.

A. R. LyONS

M. C. R. SYMONS

Department of Chemistry,

S. P. Mishra

The University,

Leicester LE1 7RH, UK.

Received October 8, 1973.

'Egland, R. J., Ogren, P. J., and Willard, E. E., J. phys. Chem., 75, 467 (1971) and references therein.

${ }^{2}$ Electron Spin Resonance, Vol. I (edit. by Norman, R. O. C.) Chemical Society Specialist Report, 130 (London, 1973).

${ }^{3}$ Kispert, L. D., and Myers, F., J. chem. Phys., 56, 2623 (1972).

${ }^{4}$ Mishra, S. P., Neilson, G. W., and Symons, M. C. R., J. Am. chem. Soc., 95, 605 (1973).

${ }^{5}$ Lyons, A. R., and Symons, M. C. R., J. Am. chem. Soc., 93, 7330 (1971).

${ }^{6}$ Sprague, E. D., and Williams, F., J. chem. Phys., 54, 5425 (1971).

7 Mishra, S. P., and Symons, M. C. R., J. chem. Soc., Perkin II, 391 (1973).

\section{Lyoluminescence of trehalose dihydrate}

LYOLUMINESCENCE of trehalose. $2 \mathrm{H}_{2} \mathrm{O}$ in water has been observed over a wide range of radiation doses. It has been possible to cover linearly the range from $10 \mathrm{rad}$ up to 150 krad. With some samples the lower limit was $100 \mathrm{mrad}$.

The emission of light when irradiated saccharides are dissolved in water has been described ${ }^{1,2}$. Saccharides were chosen because of their good solubility in water and because they are quite good soft tissue equivalent materials. Free radicals which formed during irradiation of the solid probably cause the light emission when they are set free to react in solution ${ }^{3}$.

There is evidence from our experiments that the diffusion controlled reactions involved in the process of light emission are of the type:

$$
\begin{aligned}
& \mathrm{R}+\mathrm{R}^{*} \rightarrow \mathrm{R}-\mathrm{R} \\
& \mathrm{R}+\mathrm{O}_{2} \rightarrow \mathrm{RO}_{i 2}^{*} \\
& 2 \mathrm{RO}_{2}^{*} \rightarrow \mathrm{R}-\mathrm{R}+\left(\mathrm{O}_{2}\right)_{2}^{*}
\end{aligned}
$$

This is based on the several observations.

(1) The emission spectrum of all saccharides (for example, trehalose. $2 \mathrm{H}_{2} \mathrm{O}$, glucose, mannose) has a maximum at approximately $4,900 \AA$ as determined by interference filters. This coincides with the absorption peaks of the $\mathrm{S} \rightarrow \mathrm{T}$ transition of $\left(\mathrm{O}_{2}\right)_{2}$ associate 4 .

(2) When irradiated saccharides are annealed at different temperatures, they tend to exhibit more lyoluminescence. This is a result of the temperature-assisted diffusion of $\mathrm{O}_{2}$ during annealing. 